\title{
TRIACETIN PRODUCTION FROM GLYCEROL USING HETEROGENEOUS CATALYSTS PREPARED FROM PEAT CLAY
}

\author{
Noor Ridha Yanti ${ }^{1}$, Hesty Heryani ${ }^{2 *}$, Meilana Dharma Putra ${ }^{3}$, Agung Nugroho ${ }^{2}$ \\ ${ }^{1}$ Department of Natural and Environmental Resources Management, Graduate Program, University \\ of Lambung Mangkurat, Banjarbaru 70714, Indonesia \\ ${ }^{2}$ Department of Agro-industrial Technology, Faculty of Agriculture, University of Lambung Mangkurat, \\ Banjarbaru 70714, Indonesia \\ ${ }^{3}$ Department of Chemical Engineering, Faculty of Engineering, University of Lambung Mangkurat, \\ Banjarbaru 70714, Indonesia
}

(Received: December 2018 / Revised: March 2019 / Accepted: May 2019)

\begin{abstract}
Glycerol, an abundant by-product of biodiesel production, is urgently considered to increase its usage. Triacetin produced from glycerol is an important material, used in polyester, cryogenics, cosmetics and as a biodiesel additive. Using homogeneous catalysts in triacetin production involves high product separation costs. The purpose of this study is to synthesize heterogeneous catalysts based on alumina and silica from peat clay for use in the production of triacetin from glycerol. The conversion of glycerol for triacetin production using such alumina and silica catalysts yielded levels of $82.7 \%$ and $87.4 \%$, respectively. These values were greater than the conversion value of $71.2 \%$ using a sulfuric acid homogeneous catalyst. An optimum conversion of $91 \%$ was obtained at the mole ratio of glycerol to acetic acid of 8.9. The potential heterogeneous catalysts were confirmed by the results of SEM, XRD and BET characterization. Therefore, the production of triacetin using heterogeneous silica catalyst could be an alternative approach in commercial processes which currently using homogeneous catalysts.
\end{abstract}

Keywords: Glycerol; Heterogeneous catalyst; Peat clay; Triacetin

\section{INTRODUCTION}

Much attention is being paid to the limitations of fossil energy such as oil and coal, leading to the development of renewable energy. For the last two decades, alternative fuels have been developed to meet the rapidly increasing energy consumption needs. Biodiesel, one of the promising alternative and renewable fuels, has been viewed with increasing research interest in recent years as a form of renewable energy (Srithar et al., 2017). Tests on the use of biodiesel in diesel engine performance have been conducted (Susila et al., 2012) using a mixture of diesel fuel with biodiesel from vegetable oil sources, i.e rubber seed oil. Engine tests have shown that the B-20 (rubber seed oil methyl ester catalytic method dry wash system) mixture produced the best engine performance at $2550 \mathrm{rpm}$. The emission levels produced were more environmentally friendly than those from diesel fuel. Biodiesel production would generate about $10 \%(\mathrm{w} / \mathrm{w})$ glycerol as the main byproduct; in other words, every gallon of biodiesel generates approximately 1.05 pounds of glycerol (San Kong et al., 2016). Glycerol as a byproduct of biodiesel products, which is effective to be a useful chemical, is needed to reduce environmental pollution (Srithar et al., 2017).

\footnotetext{
*Corresponding author's email: hheryani@ulm.ac.id, Tel. +65-11-4772254, Fax.+65-11-4772254 Permalink/DOI: https://doi.org/10.14716/ijtech.v10i5.2685
} 
A study on glycerol conduct by Saksono et al. (2012) investigated the effectiveness of plasma electrolysis on hydrogen product quantity and energy consumption. Their results showed that an increase in voltage led to increased hydrogen production and energy consumption, and that the addition of glycerol resulted in a decrease in hydrogen production, but an increase in energy consumption. Moreover, according to Slamet et al. (2015), alternative method with metal oxide and non-metallic oxide, which has been developed in the modification of $\mathrm{TiO}_{2}$ photocatalyst from a mixture of glycerol-water to produce $\mathrm{H}_{2}$ with conversion from glycerol.Crude glycerol can be utilized for production of pyrolyzed oil using a microwave heating technique with a coconut shell-based activated carbon catalyst. The derived liquid and gaseous pyrolysis products in the range of $15-42 \%$ and $55-82 \%$ could be potential alternative fuels in combustion systems (Leong et al., 2016). Recently, the conversion of glycerol into products such as triacetin through an esterification process has been under development. Triacetin is of particular interest due to its wide applications in polyester, cryogenics, cosmetics, as an additive in biodiesel, and as a fuel additive to waste cooking biodiesel (Khayoon \& Hameed, 2011; San Kong et al., 2016; Zare et al., 2016).

Production of triacetin from glycerol can be easily processed using homogeneous acid catalysts such as $\mathrm{H}_{2} \mathrm{SO}_{4}, \mathrm{HCl}, \mathrm{HNO}_{3}$ or $\mathrm{H}_{3} \mathrm{PO}_{4}$ (Khayoon \& Hameed, 2011). However, the catalyst could cause corrosion in industrial equipment and also have a toxic impact on the environment (San Kong et al., 2016). Moreover, such a catalyst involves a complex separation process, thus contributing to the high costs. Various heterogeneous catalysts have been studied to produce triacetin from glycerol and their efficiencies classified into different groups: ion exchange resin, zeolites, heteropolyacids, metal oxides, mesoporous silica, amberlist, carbon, alumina, zirconia and the nano-silica $\left(\mathrm{SiO}_{2}\right)$ co-precipitation method using a high-energy grinding technique (Zhou et al., 2012; Jalil et al., 2016; Rane et al., 2016; San Kong et al., 2016). However, the use of these commercial synthesis catalysts has a major disadvantage, its high cost (Zhou et al., 2012). The price of commercial synthesis catalysts in the chemical industry was USD $0.98-$ $1.65 / \mathrm{kg}$ (San Kong et al., 2016). However, since the industry's needs are growing rapidly, the price of catalysts reaches USD $20-40 / \mathrm{kg}$.

One potential resource that can be considered as a heterogeneous catalyst is peat clay. This is a crystal-shaped and layered structure with particles smaller than $2 \mu \mathrm{m}$. It is located under peat soil at a depth of 1.5-3 meters below ground level and contains alumina and silica, hence its potential use as a catalyst or support (Uddin, 2017). The peat clay in South Kalimantan, Indonesia has characteristics such as weight of soil volume of $0.964 \mathrm{gcm}^{-3}$; specific gravity of 1.381 ; void ratio of 6.891 ; organic contents $95.380 \%$; fiber contents $61.330 \%$; ash content $4.620 \%$; acidity of $\mathrm{pH} 3-5$; and moisture content $67.732 \%$ at $60^{\circ} \mathrm{C}$ (Nurdin, 2011; Ma'ruf \& Yulianto, 2016).

The purpose of this study is to synthesize alumina and silica based heterogeneous catalysts derived from peat clay. The study also characterizes these catalysts, including their catalyst components, crystallinity, pore size and morphology. The catalysts are further tested for the production of triacetin from glycerol and acetic acid.

\section{EXPERIMENTAL PROCEDURES}

\subsection{Peat Clay Preparation}

The peat clay samples taken were located geographically at $3^{\circ} 25^{\prime} 25.3^{\prime \prime} \mathrm{S} ; 114^{\circ} 43^{\prime} 38.6^{\prime \prime} \mathrm{E}$, Banjarbaru, South Kalimantan. The clay was dried until the water content was reduced $(\leq 5 \%)$, and then mashed with a porcelain mortar and passed through a 80-mesh sieve. It was subsequently calcined in a furnace at $800^{\circ} \mathrm{C}$ for 4 hours and then crushed and sifted to 200 mesh. 


\subsection{Extraction Process and Catalyst Synthesis}

The calcined peat clay ash was dissolved with $6 \mathrm{~N} \mathrm{HCl}$ and $2.5 \mathrm{M} \mathrm{NaOH}$ at a ratio of 1:5 (b/v) to extract the alumina and silica. A leaching process was then performed at $90^{\circ} \mathrm{C}$ for 24 hours. $0.1 \mathrm{~N} \mathrm{NaOH}$ (for alumina extraction) and $0.1 \mathrm{~N} \mathrm{HCl}$ (for silica extraction) were then added to the filtrate to produce a neutral $\mathrm{pH} 7$. The precipitate formed was separated from the filtrate using filter paper, then washed twice with distilled water and dried in an oven at $60^{\circ} \mathrm{C}$ for 24 hours until the mass was uniform. Subsequently, the dried precipitate was calcined at $700^{\circ} \mathrm{C}$ for 4 hours, until alumina and silica crystals were finally obtained.

\subsection{Production of Triacetin}

Glycerol was heated in three neck flasks to a temperature of $90^{\circ} \mathrm{C}$ and acetic acid was then added with variations in the volume ratio of glycerol to acetic acid of 1:5 (equal mol ratio of 1:6.6); 1:7 (equal mol ratio of 1:8.9); and 1:9 (equal mol ratio of 1:11.5). 5\% wt (based on glycerol) extracted alumina or silica as a heterogeneous catalyst was then added. Next, the mixed solution was reacted at $90^{\circ} \mathrm{C}$ and at $300 \mathrm{rpm}$ for 3 hours. The filtrate from the esterification process was separated from the catalyst by filtration. The titration method was used to measure the quantitative glycerol conversion as described by Tamborini et al. (2015). In this study, glycerol conversion was calculated using the following formula from Equation 1. and Equation 2 to determine the conversion vs. time. The catalytic activity was expressed as the conversion of oleic and acetic acid (X\%) (Tamborini et al., 2015):

$$
\begin{aligned}
& (X \%)=\frac{\text { mol HAc initial }- \text { mol HAc end }}{\text { mol HAc initial }} \times 100 \% \\
& (X \%)=\frac{\text { mol Hol initial }- \text { mol Hol end }}{\text { mol HOl initial }} \times 100 \%
\end{aligned}
$$

\subsection{Characterization}

The heterogeneous catalyst was characterized by analysis of its crystallographic structure based on its amorphous or crystalline properties using X-ray diffraction (XRD); analysis of the specific surface area; total pore volume; average pore finger using Brunauer-Emmett-Teller (BET); and analysis of the surface morphology and particle size using a Scanning Electron Microscopy-Energy Dispersive X-Ray Spectrometer (SEM-EDX).

\section{RESULTS AND DISCUSSION}

\subsection{Yield of Extracted Alumina and Silica}

Figure 1 shows the yield of alumina and silica extracted from the peat clay. That of silica, at $14.3 \%$, was greater than the $9.6 \%$ of alumina. This was due to the degradation of iron oxide content, resulting in the significant addition of iron ions, causing the release of several inorganic or organic impurities during the isolation of the peat clay alumina. According to Notodarmojo (2005), clay is generally dominated by phyllosilicate formed of silica minerals, containing oxygen and hydroxyl anions related with aluminum cations and silicon, so there was a crystal side of the clay which formed a surface that was reactive in absorbing iron ions and Mn. The results of this study did not differ greatly from those of Ruslan and Mirzan (2017), who carried out clay pilarization (bentonite) and obtained $6.1 \%$ alumina and $26.2 \%$ silica. It is possible that the greater concentration of hydrochloric acid $(\mathrm{HCl})$ led to the lower percentage of alumina content; during the leaching process, $\mathrm{Cl}^{-}$ions from the hydrochloric acid solvent bind $\mathrm{Al}^{3+}$ ions and form $\mathrm{AlCl}_{3}$, thus more alumina dissolves in the hydrochloric acid and produces chlorine components as an inorganic impurity. On the other hand, the silica was easily soluble in alkaline solutions, especially $\mathrm{NaOH}$, and was able to penetrate the capillaries in ash and consequently dissolve the silica. According to Pinna et al. (2017), the magnitude of the 
concentration of alkaline solution will affect the power to dissolve the solute; the greater the concentration of the alkaline solution, the greater the yield produced.

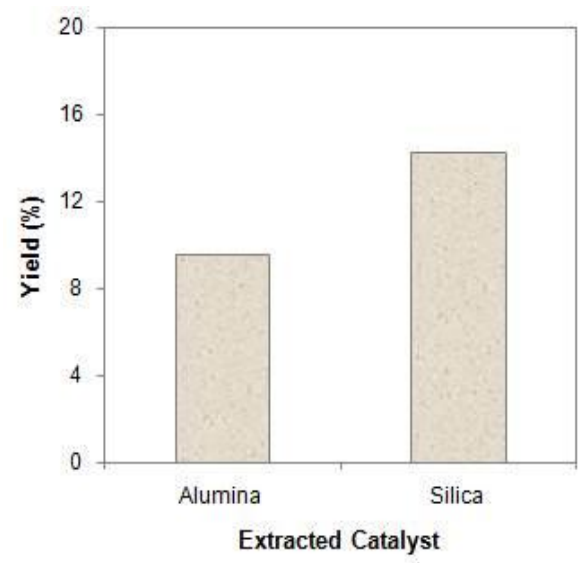

Figure 1 Extraction of alumina and silica from peat clay

\subsection{Characterization Results of the Extracted Alumina and Silica}

Figure 2 shows the characterization results of the alumina and silica extracted. Crystallinity is indicated by sharp and narrow peaks, showing the existence of the crystal phase. In Table 1, the XRD pattern of the alumina catalyst has the appearance of the peak $\gamma$-alumina, namely at $40.506^{\circ}, 45.3684^{\circ}$ and $66.2741^{\circ}$. Based on JCPDS card No. 10-0425, typical peaks of $\gamma-$ alumina are observed at $39.492^{\circ}, 45.86^{\circ}$ and $67.03^{\circ}$. This shows that the synthesis of alumina catalyst calcined at $700^{\circ} \mathrm{C}$ did not change the peak position of the diffractogram; therefore, there was similarity in the phase structure of the $\gamma$-alumina crystals produced. This is in accordance with the results obtained by Segal et al. (2018), who found that gamma alumina (Al$\mathrm{Al}_{2} \mathrm{O}_{3}$ ) synthesized at $700^{\circ} \mathrm{C}$ had good crystallinity. Sun et al. (2008) and Hartmann et al. (2012) also revealed that alumina samples calcined at $500^{\circ} \mathrm{C}$ and $800^{\circ} \mathrm{C}$ had peak characteristics with small and narrow angles, indicating that the properties and structure of the sample persisted during calcination. It also shows that the samples had mesoporous properties.

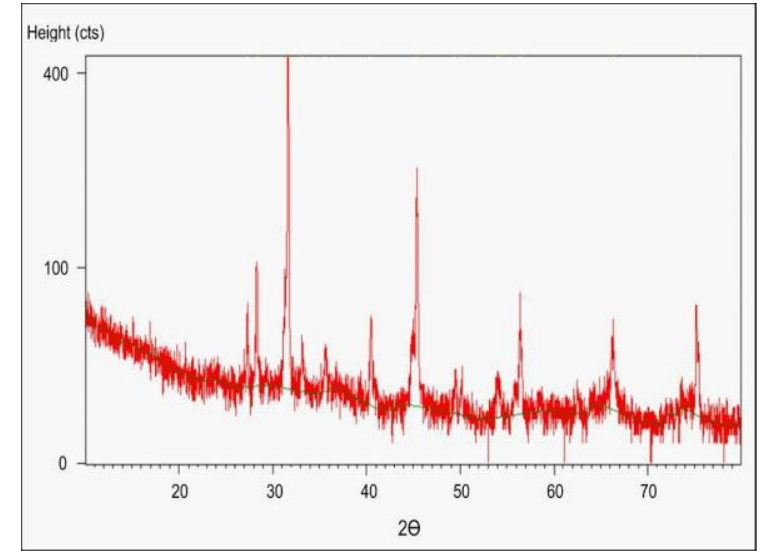

(a)

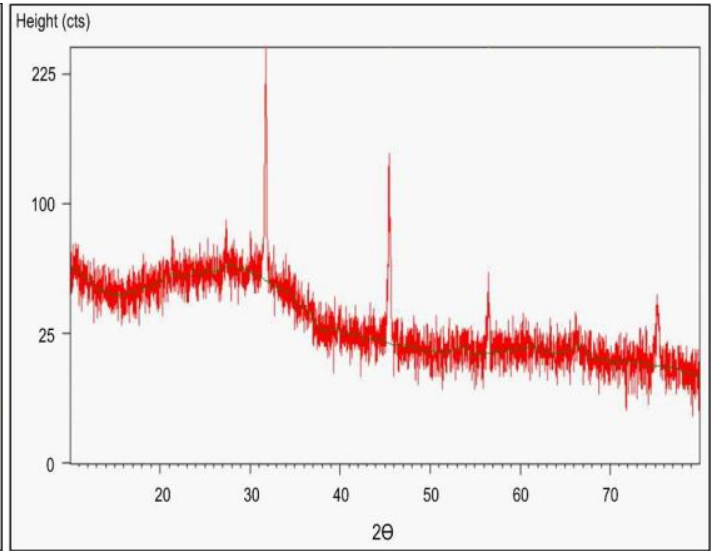

(b)

Figure 2 XRD characterization results for: (a) alumina catalyst; and (b) silica catalyst

The peaks in the XRD characterization results for silica are indicated by an $\mathrm{SiO}_{2}$ phase with $2 \theta$ at $45.4608^{\circ}, 56.4973^{\circ}$ and $75.3054^{\circ}$. Based on JCPDS card No. 46-1045, the typical peaks of $\mathrm{SiO}_{2}$ are observed with $2 \theta$ at $45.793^{\circ}, 55.325^{\circ}$ and $75.660^{\circ}$. This shows that the characteristics of silica catalyst calcined at $700^{\circ} \mathrm{C}$ formed a sharp and narrow diffactogram peak with high 
intensity; therefore, the $\mathrm{SiO}_{2}$ phase is confirmed. This finding is in line with the results obtained by Kusumawati et al. (2018), that a peak in the $\mathrm{SiO}_{2}$ phase was observed after calcination at a temperature of $700^{\circ} \mathrm{C}$.

Table 1 Difractogram peaks for alumina and silica catalysts

\begin{tabular}{lcccc}
\hline \multirow{2}{*}{ Phase } & \multicolumn{3}{c}{ Difractogram peak } & \multirow{2}{*}{ Reference } \\
\cline { 2 - 4 }$\gamma$-alumina standard & 39 & $2 \theta$ & $2 \theta$ & \\
\hline Extracted $\gamma$-alumina & $40.51^{\circ}$ & $45.37^{\circ}$ & $66.27^{\circ}$ & This research \\
\hline $\mathrm{SiO}_{2}$ standard & $45.79^{\circ}$ & $55.36^{\circ}$ & $75.66^{\circ}$ & $\begin{array}{c}\text { JCPDS } \\
\text { No. 46-2045 }\end{array}$ \\
\hline Extracted $\mathrm{SiO}_{2}$ & $45.46^{\circ}$ & $56.50^{\circ}$ & $75.31^{\circ}$ & This research \\
\hline
\end{tabular}

Characterization of surface area and pore size was made using the Brunauer Emmett Teller (BET) method. Surface area was calculated with the multipoint BET equation in the P/Po range of 0.05-0.35, while pore volume was calculated from the maximum adsorption amount of nitrogen at a P/Po of 0.99 (Kuila \& Prasad, 2013). The nitrogen adsorption-desorption isotherm by alumina catalyst and silica catalyst can be seen in Figure 3. The trend of nitrogen adsorption isotherms for both the alumina and silica catalysts was similar, with a rapid increase in volume adsorbed at low relative pressure ( $\mathrm{P} / \mathrm{Po})$. This then slowly rose in the middle range of $\mathrm{P} / \mathrm{Po}$ and rose again more rapidly at high $\mathrm{P} / \mathrm{Po}$. It is possible that at a relative pressure of $0.07-0.43$ the gas adsorbed interacts with the active site of the solid surface. Consequently, the surface of the solid would be covered by nitrogen molecules to form a single layer (monolayer). Finally, a multilayer layer was formed at the end of filling; there was condensation of the adsorbed gas molecules, and overall there was a hysteresis loop in the middle region. According to Kuila et al. (2014), a hysteresis loop occurs at a relative pressure of 0.55 to 0.8 , meaning that the porous size distribution is almost identical in the range of 3-6 nm. The adsorption isotherm for the alumina and silica catalysts shows a type IV adsorption isotherm profile, which is typically the characteristic of mesoporous solids. Type IV isotherms describe the type of adsorption for mesoporous solids with a pore size of 2-50 $\mathrm{nm}$. This finding was supported by the pore size results from Brunauer Emmett Teller (BET), as presented in Table 2.

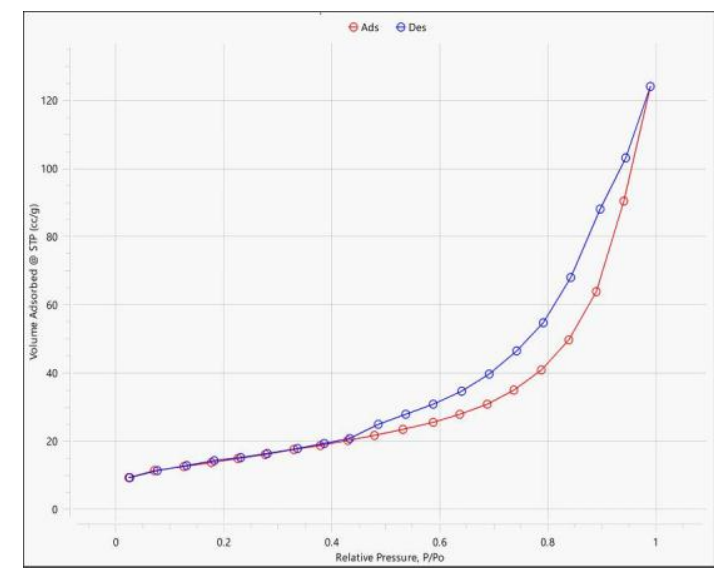

(a)

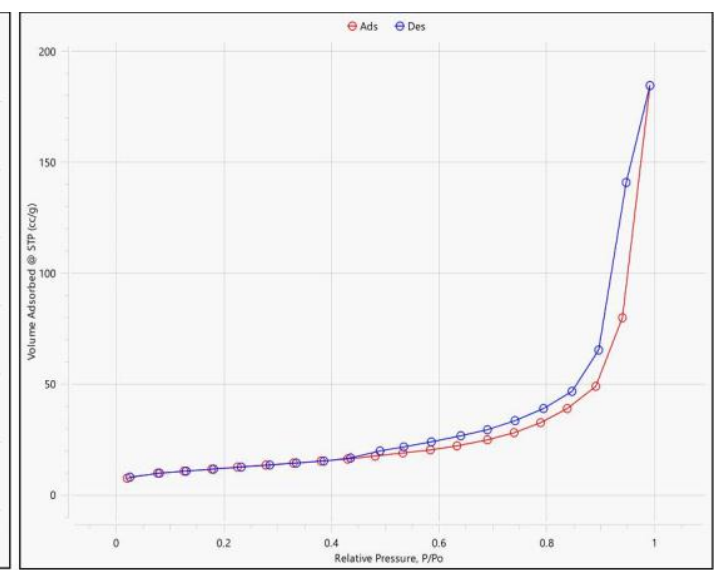

(b)

Figure 3 Isoterm adsorption-desorption $\mathrm{N}_{2}$ for (a) alumina catalyst and (b) silica catalyst 
Table 2 Pore size and surface area for alumina and silica catalyst

\begin{tabular}{lcccc}
\hline Type of Catalyst & $\begin{array}{c}\text { Pore size } \\
(\mathrm{nm})\end{array}$ & Reference & $\begin{array}{c}\text { Surface area } \\
\left(\mathrm{m}^{2} \mathrm{~g}^{-1}\right)\end{array}$ & Reference \\
\hline$\gamma-\mathrm{Al}_{2} \mathrm{O}_{3}$ & 5.37 & This research & 52.3142 & This research \\
\hline $\begin{array}{l}\mathrm{Mesoporous} \text { alumina } \\
\left(\gamma-\mathrm{Al}_{2} \mathrm{O}_{3}\right)\end{array}$ & $3.6-6.4$ & $\begin{array}{c}\text { Chen et al. } \\
(2017)\end{array}$ & $<250$ & Chen et al. $(2017)$ \\
\hline $\mathrm{SiO}_{2}$ & 5.68 & This research & 43.57 & This research \\
\hline $\mathrm{SiO}_{2}$ mesoporous & $2.4-6.5$ & $\begin{array}{c}\text { Huang et al. } \\
(2014)\end{array}$ & $12-67$ & $\begin{array}{c}\text { Faramawy et al. } \\
(2016)\end{array}$ \\
\hline
\end{tabular}

Table 2 shows a pore size of the gamma phase alumina catalyst $(\gamma)$ of $5.36745 \mathrm{~nm}$. This means that the activation process and calcination at $700^{\circ} \mathrm{C}$ could change the pore size of the crystals, in which the evaporation of water is trapped in the pores of the peat clay crystals, while the pore size of the catalyst produced included the type of mesopore below $50 \mathrm{~nm}$. The alumina catalyst had a lower surface area of $52.31 \mathrm{~m}^{2} \mathrm{~g}^{-1}$ compared to industrial alumina catalyst $\left(<250 \mathrm{~m}^{2} \mathrm{~g}^{-1}\right)$. The surface area of silica obtained in this study was also comparable to that reported in the literature; by Faramawy et al. (2016), with a surface area of $12-67 \mathrm{~m}^{2} \mathrm{~g}^{-1}$, and Putra et al. (2017), who produced silica catalyst with a surface area of $39.7 \mathrm{~m}^{2} \mathrm{~g}^{-1}$.

Figure 4 shows the results of the SEM characterization for the alumina and silica catalysts. In the figure they show regular small lumps with a larger surface area. This corresponds to the XRD test results, which show both catalysts have fairly regular crystallinity. The magnitude of the specific surface area of clay is one of the prerequisites for its use as a catalyst, because the surface is a medium for the reaction, thus leading to a rapid reaction (Kuila \& Prasad, 2013).

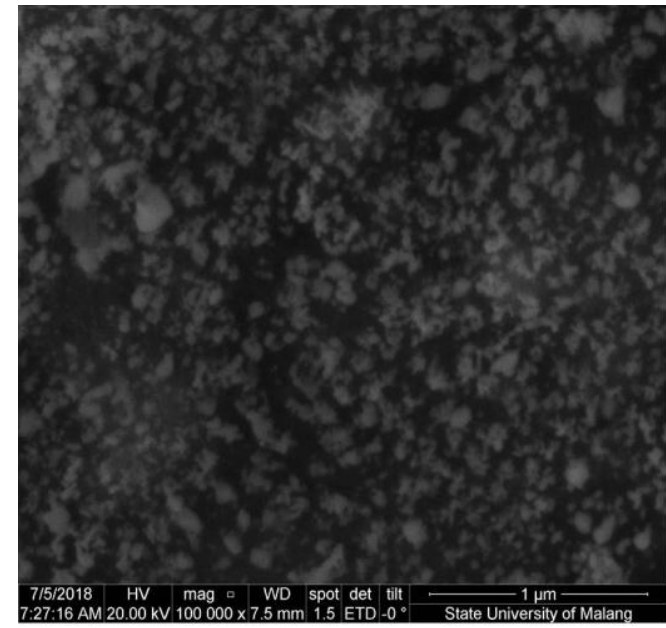

(a)

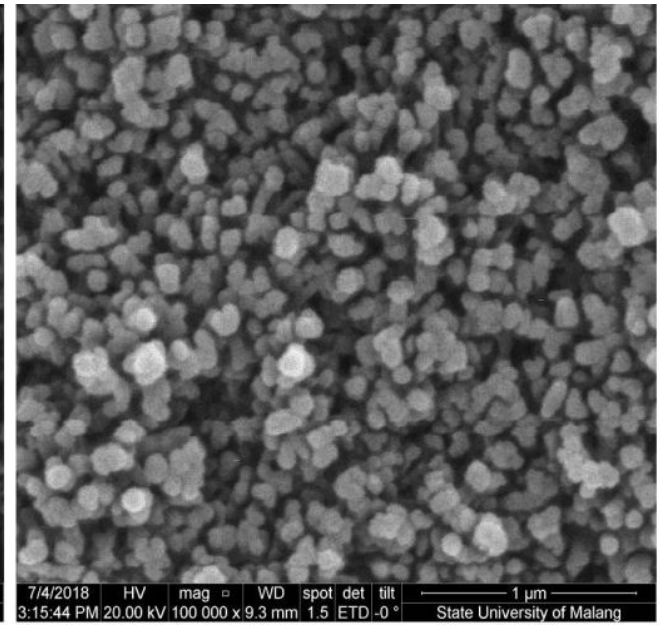

(b)

Figure 4 SEM characterization results for: (a) alumina catalyst; and (b) silica catalyst

\subsection{Effect of Type of Catalyst on Glycerol Conversion}

Figure 5 shows the conversion of glycerol for the production of triacetin using several types of catalyst. The homogeneous sulfuric acid catalyst shows a fairly large conversion value of $71.2 \%$. The magnitude of this conversion is common because homogeneous catalysts have the same phase as the reactants, hence accelerating the reaction rate. The heterogeneous alumina and silica catalysts resulted in higher conversions of $82.73 \%$ and $87.40 \%$. These results prove that alumina and silica-solid catalysts are able to effectively convert glycerol into triacetin. Therefore, this could reduce the separation process cost for systems using homogeneous catalysts. The results are comparable with those obtained by Setyaningsih et al. (2018), who 
used heterogenous catalysts with a conversion range of $70-98 \%$ depending on the other parameters.

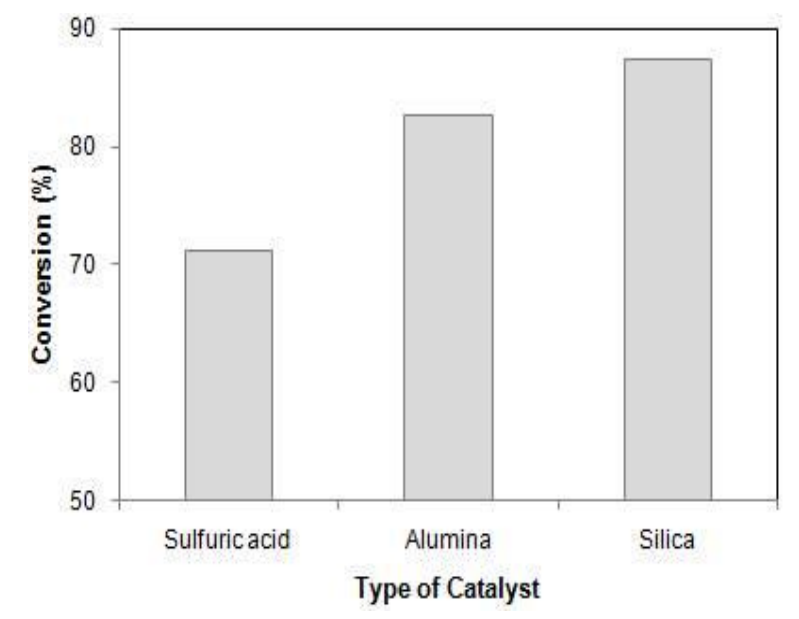

Figure 5 Effect of type of catalyst on glycerol conversion

\subsection{Effect of Mole Ratio on Glycerol Conversion}

Figure 6 shows the conversion of glycerol in triacetin production to the effect of mole ratio of reactants using silica catalyst. Increasing the mole ratio from 6.6 to 8.9 increased conversion from $83 \%$ to $91 \%$. This was reasonable, because the increase in the mole ratio caused more collisions between the reactant molecules, so consequently an increase in the reaction rate. This finding is consistent with previous research, which has found an increase in conversion at a mole ratio 5:9 (Rafi et al., 2015) and also at 6:8 (Setyaningsih et al., 2018). However, a small decrease in conversion was obtained when the ratio was increased from 1:8.9 to $1: 11.5$ from $91 \%$ to $87 \%$, as shown in Figure 6 . This was possibly due to a saturation condition at the high mole ratio, so insignificant changes occurred. This is also in accordance with the study by Rane et al. (2016), who found no significant effect of the range of 8-10 mole ratio of glycerol conversion.

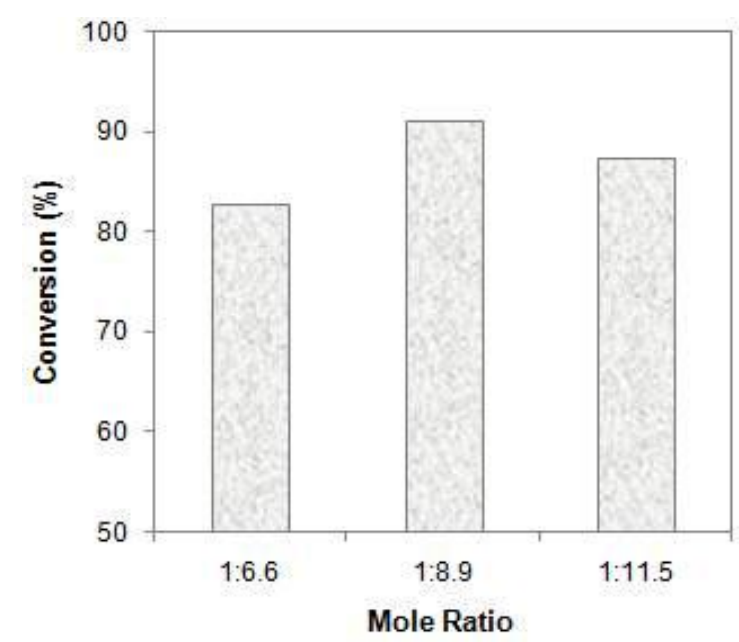

Figure 6 Effect of mole ratio on glycerol conversion

\section{CONCLUSION}

Extraction of alumina and silica from peat clay resulted in yields of $9.60 \%$ and $14.29 \%$, respectively. The utilization of silica catalyst in the esterification reaction for the production of 
triacetin from glycerol led to the highest conversion of glycerol, at $87.40 \%$, compared to the utilization of alumina and sulfuric acid catalysts. The mole ratio of 1:8.9 for the silica catalyst reactant gave the highest glycerol conversion of $91.61 \%$. The results obtained in this study for the production of triacetin using heterogeneous silica catalyst could be an alternative approach to commercial processes using homogeneous catalysts.

\section{ACKNOWLEDGEMENT}

The authors thank the Graduate Program at Lambung Mangkurat University for supporting the work.

\section{REFERENCES}

Chen, Z., Weinberger, C., Tiemann, M., Kuckling, D., 2017. Organic Polymers as Porogenic Structure Matrices for Mesoporous Alumina and Magnesia. Processes, Volume 5(4), pp. $1-10$

Faramawy, S., El-Naggar, A., El-Fadly, A., El-Sabagh, S., Ibrahim, A., 2016. Silica, Alumina and Aluminosilicates as Solid Stationary Phases in Gas Chromatography. Arabian Journal of Chemistry, Volume 9, pp. S765-S775

Hartmann, S., Sachse, A., Galarneau, A., 2012. Challenges and Strategies in the Synthesis of Mesoporous Alumina Powders and Hierarchical Alumina Monoliths. Materials, Volume 5(2), pp. 336-349

Huang, X., Young, N.P., Townley, H.E., 2014. Characterization and Comparison of Mesoporous Silica Particles for Optimized Drug Delivery. Nanomaterials and Nanotechnology, Volume 4(2), pp. 1-15

Jalil, Z., Rahwanto, A., Mulana, F., Mustanir., 2016. Desorption Temperature Characteristic of Mg-based Hydrides Catalyzed by $\mathrm{Nano}_{-} \mathrm{SiO}_{2}$ Prepared by High Energy Ball Milling. International Journal of Technology, Volume 7(8), pp. 1301-1306

Khayoon, M., Hameed, B., 2011. Acetylation of Glycerol to Biofuel Additives Over Sulfated Activated Carbon Catalyst. Bioresource Technology, Volume 102(19), pp. 9229-9235

Kuila, U., McCarty, D.K., Derkowski, A., Fischer, T.B., Topór, T., Prasad, M., 2014. Nanoscale Texture and Porosity of Organic Matter and Clay Minerals in Organic-Rich Mudrocks. Fuel, Volume 135, pp. 359-373

Kuila, U., Prasad, M., 2013. Specific Surface Area and Pore-size Distribution in Clays and Shales. Geophysical Prospecting, Volume 61(2), pp. 341-362

Kusumawati, D.H., Putri, N.P., Hidayat, N., Taufiq, A., Supardi, Z.A.I., 2018. Synthesis and Characterization of $\gamma-\mathrm{Al}_{2} \mathrm{O}_{3} / \mathrm{SiO}_{2}$ Composite Materials. Journal of Physics, Volume 1093(Conference 1), pp. 1-7

Leong, S.K., Lam, S.S., Ani, F.N., Ng, J.-H., Chong, C.T., 2016. Production of Pyrolyzed Oil from Crude Glycerol using a Microwave Heating Technique. International Journal of Technology, Volume 7(2), pp. 323-331

Ma'ruf, M.A., Yulianto, F.E., 2016. Fibrous Peat Soil: Solutions and Its Problems in Development of Environmental Infrastructure. In: Proceedings of the Geotechnical National Seminar 2016, pp. 279-292

Notodarmojo, S., 2005. Soil and Groundwater Pollution. Bandung: ITB Publisher

Nurdin, S., 2011. Analysis of Changes in Water Content and Shear Strength of Lalombi Peat Soils Due to Effect of Temperature and Heating Time. Smartek, Volume 9(2), pp. 88-108

Pinna, E.G., Suarez, D.S., Rosales, G.D., Rodriguez, M.H., 2017. Hydrometallurgical Extraction of $\mathrm{Al}$ and Si From Kaolinitic Clays. REM-International Engineering Journal, Volume 70(4), pp. 451-457 
Putra, M.D., Ristianingsih, Y., Jelita, R., Irawan, C., Nata, I.F., 2017. Potential Waste from Palm Empty Fruit Bunches and Eggshells as a Heterogeneous Catalyst for Biodiesel Production. RSC Advances, Volume 7(87), pp. 55547-55554

Rafi, J.M., Rajashekar, A., Srinivas, M., Rao, B., Prasad, R., Lingaiah, N., 2015. Esterification of Glycerol Over a Solid Acid Biochar Catalyst Derived from Waste Biomass. RSC Advances, Volume 5(55), pp. 44550-44556

Rane, S., Pudi, S., Biswas, P., 2016. Esterification of Glycerol with Acetic Acid Over Highly Active and Stable Alumina-based Catalysts: A Reaction Kinetics Study. Chemical and Biochemical Engineering Quarterly, Volume 30(1), pp. 33-45

Ruslan, J.H., Mirzan, M., 2017. Synthesis and Characterization of Sulfated Zirconate Clay Catalyst as a Brass Catalyst. In: Proceedings of the National Chemistry Seminar: Synergy of Research and Learning to Support the Development of Chemical Literacy in the Global Era, pp. 325-334

Saksono, N., Ariawan, B., Bismo, S., 2012. Hydrogen Productions System using Non-thermal Plasma Electrolysis in Glycerol-KOH Solution. International Journal of Technology, Volume 1(1), pp. 8-15

San Kong, P., Aroua, M.K., Daud, W.M.A.W., Lee, H.V., Cognet, P., Pérès, Y., 2016. Catalytic Role of Solid Acid Catalysts in Glycerol Acetylation for the Production of Bio-additives: A Review. RSC Advances, Volume 6(73), pp. 68885-68905

Segal, F.M., Correa, M.F., Bacani, R., Castanheira, B., Politi, M.J., Brochsztain, S., Triboni, E.R., 2018. A Novel Synthesis Route of Mesoporous $\gamma$-Alumina from Polyoxohydroxide Aluminum. Materials Research, Voulme 21(1), pp. 1-8

Setyaningsih, L., Siddiq, F., Pramezy, A. 2018., Esterification of Glycerol with Acetic Acid Over Lewatit Catalyst. In: MATEC Web of Conferences, Volume 154

Slamet, S., Kusrini, E., Salim Afrozi, A., Ibadurrohman, M., 2015. Photocatalytic Hydrogen Production from Glycerol-water over Metal Loaded and Non-metal Doped Titanium Oxide. International Journal of Technology, Volume 6(4), pp. 520-532

Srithar, K., Balasubramanian, K.A., Pavendan, V., Kumar, B.A., 2017. Experimental Investigations on Mixing of Two Biodiesels Blended with Diesel as Alternative Fuel for Diesel Engines. Journal of King Saud University-Engineering Sciences, Volume 29(1), pp. $50-56$

Susila, I.W., Rachimoellah, R., Sutantra, I., 2012. The Performance of Diesel Engine using Biodiesel Fuel from Rubber Seed Oil Production by Catalytic Method. International Journal of Technology, Volume 3(1), pp. 24-34

Sun, Z.-X., Zheng, T.-T., Bo, Q.-B., Du, M., Forsling, W., 2008. Effects of Calcination Temperature on the Pore Size and Wall Crystalline Structure of Mesoporous Alumina. Journal of Colloid and Interface Science, Volume 319(1), pp. 247-251

Tamborini, L., Militello, M., Balach, J., Moyano, J., Barbero, C., Acevedo, D., 2015. Application of Sulfonated Nanoporous Carbons as Acid Catalysts for Fischer Esterification Reactions. Arabian Journal of Chemistry, Volume 6, pp. 1-11

Uddin, M.K., 2017. A Review on the Adsorption of Heavy Metals by Clay Minerals, with Special Focus on the Past Decade. Chemical Engineering Journal, Volume 308, pp. 438-462

Zare, A., Nabi, M.N., Bodisco, T.A., Hossain, F.M., Rahman, M.M., Ristovski, Z.D., Brown, R.J., 2016. The Effect of Triacetin as a Fuel Additive to Waste Cooking Biodiesel on Engine Performance and Exhaust Emissions. Fuel, Volume 182, pp. 640-649

Zhou, L., Nguyen, T.-H., Adesina, A.A., 2012. The Acetylation of Glycerol Over Amberlyst15: Kinetic and Product Distribution. Fuel Processing Technology, Volume 104, pp. 310-318 